\title{
Will work for snack food: The association of BMI and snack reinforcement
}

Citation for published version (APA):

Giesen, J. C. A. H., Havermans, R. C., Douven, A., Tekelenburg, M., \& Jansen, A. T. M. (2010). Will work for snack food: The association of BMl and snack reinforcement. Obesity, 18(5), 966-970.

https://doi.org/10.1038/oby.2010.20

Document status and date:

Published: 01/01/2010

DOI:

10.1038/oby. 2010.20

Document Version:

Publisher's PDF, also known as Version of record

Document license:

Taverne

Please check the document version of this publication:

- A submitted manuscript is the version of the article upon submission and before peer-review. There can be important differences between the submitted version and the official published version of record.

People interested in the research are advised to contact the author for the final version of the publication, or visit the DOI to the publisher's website.

- The final author version and the galley proof are versions of the publication after peer review.

- The final published version features the final layout of the paper including the volume, issue and page numbers.

Link to publication

\footnotetext{
General rights rights.

- You may freely distribute the URL identifying the publication in the public portal. please follow below link for the End User Agreement:

www.umlib.nl/taverne-license

Take down policy

If you believe that this document breaches copyright please contact us at:

repository@maastrichtuniversity.nl

providing details and we will investigate your claim.
}

Copyright and moral rights for the publications made accessible in the public portal are retained by the authors and/or other copyright owners and it is a condition of accessing publications that users recognise and abide by the legal requirements associated with these

- Users may download and print one copy of any publication from the public portal for the purpose of private study or research.

- You may not further distribute the material or use it for any profit-making activity or commercial gain

If the publication is distributed under the terms of Article $25 \mathrm{fa}$ of the Dutch Copyright Act, indicated by the "Taverne" license above, 

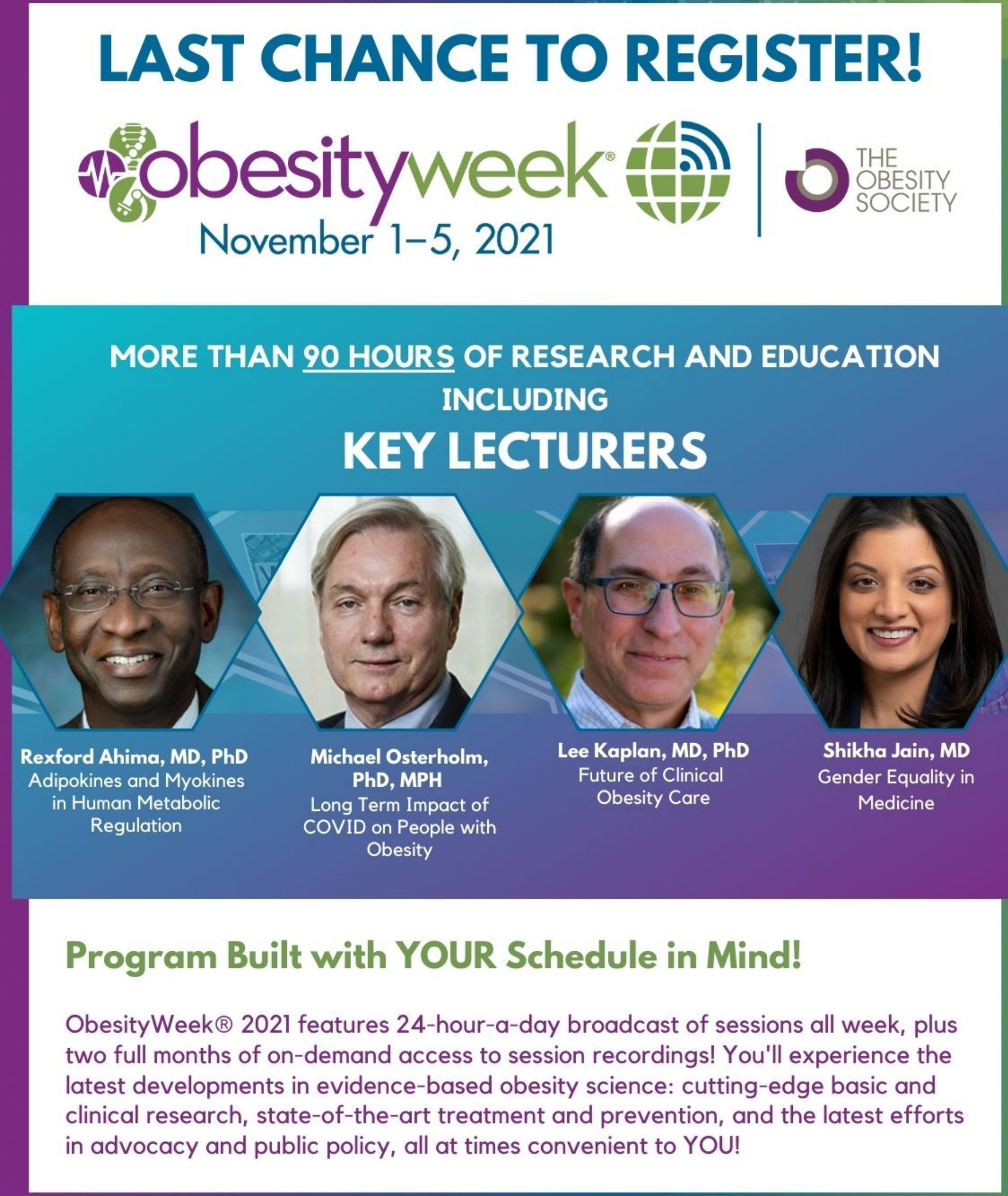

\section{View full program \& register at ObesityWeek.org/Attend}




\title{
Will Work for Snack Food: The Association of BMI and Snack Reinforcement
}

\author{
Janneke C.A.H. Giesen ${ }^{1}$, Remco C. Havermans ${ }^{1}$, Anne Douven ${ }^{1}$, Mignon Tekelenburg ${ }^{1}$ \\ and Anita Jansen ${ }^{1}$
}

\begin{abstract}
It has been suggested that for overweight and obese individuals high-calorie foods are more reinforcing than for normal-weight individuals. It has already been shown that in contrast to sedentary activities, snack food is more reinforcing for obese women, relative to normal-weight women. However, it is unclear whether overweight/obese individuals are more sensitive to the reinforcing value of food in general or more specifically to the reinforcing value of high-calorie foods. This was tested in the present study, with overweight/obese and normal-weight individuals performing a concurrent schedules task, which measures how hard someone is prepared to work for high-calorie snacks compared to low-calorie foods (e.g., fruits, vegetables), when both foods are equally liked. By gradually increasing the amount of work required to earn snacks, the relative-reinforcing value of snacks was determined. As hypothesized, overweight/obese individuals work harder for high-calorie snacks compared to normal-weight individuals.
\end{abstract}

Obesity (2010) 18, 966-970. doi:10.1038/oby.2010.20

\section{INTRODUCTION}

Generally speaking, obesity is the result of consuming more energy than expending it. The current rise in the prevalence of obesity, then, can at least partly be explained in terms of excess caloric intake (1). Obese people particularly overeat on high-calorie foods (2). But why would obese people overeat on specifically high-calorie foods? Several studies demonstrate that compared to normal-weight individuals, obese individuals show an increased preference for high-calorie foods, particularly for food items with a high-fat content (e.g., refs. 3,4). However, exactly what this apparent dietary fat preference entails is unclear.

According to Berridge $(5,6)$, when examining food reward, one should make a distinction between food liking and food wanting. Food liking refers to the palatability or pleasure obtained from tasting a given food, whereas food wanting refers to appetite or the motivation to eat. According to Berridge, these two processes can be dissociated. Mela (7) argued that with regard to understanding obesity discriminating food liking and food wanting may be very important. Indeed, there are several studies suggesting that overweight/obese individuals report a stronger liking for high-calorie foods. However, this seems to be an inconsistent finding. Mela correctly pointed out that much research has failed to demonstrate a difference in liking for foods between normal-weight and overweight individuals (see e.g., ref. 8). In a recent study with children, Hill et al. (9) found that there is no association between the liking of different types of food and obesity. Although food liking may certainly play a role in food selection and intake, the present equivocal pattern of results suggests that other processes than food liking contribute to the obese persons' caloric overconsumption. Such a process may well be food wanting and thus Mela has noted that it might be fruitful to investigate to what degree food wanting is associated with overweight/obesity.

A behavioral task that has been said to measure food wanting is a food reinforcement task (see refs. 10,11). In such a task, participants work for points that can be traded for food. However, when the task proceeds, it becomes harder to earn points. It is measured at what point someone stops working for the food, thus determining the reinforcing value of that food. A related task is a concurrent schedules task, which measures the relative-reinforcing value of food. For example, Saelens and Epstein (12) used such a task to measure the difference in reinforcing value of high-calorie foods relative to sedentary activities between obese and nonobese women. The women played a computer game in which they could earn points for high-calorie snacks and/or minutes to spend on doing a sedentary activity. Similar to the task described above is that the response requirement to earn snack points gradually increased. However, the difference between this concurrent schedule task and the food reinforcement task described earlier is that in this particular concurrent schedules task the participants cannot stop playing 
but have to keep working until a certain total amount of points is earned. The participants nonetheless can choose not to work for snacks anymore and switch to working for minutes to spend on doing a sedentary activity for which the response requirement to earn points remains low and stable. In this way the relative-reinforcing value of the snack food was determined. The results from the Saelens and Epstein (12) study showed that obese women worked for more snack points and worked harder for snack points compared to nonobese women. This shows that the relative-reinforcing value of food, or food wanting (10), is higher in obese women compared to nonobese women. However, it is still unclear whether overweight/obese individuals are more sensitive to the relative-reinforcing value of food in general or more specifically to the reinforcing value of high-calorie snack foods. To measure whether this specifically holds true for high-calorie foods and not just any food in general, one should offer low-calorie foods as the alternative to the high-calorie snack foods in the task. This has already been done in several studies, very few of which, however, included overweight/obese participants (e.g., refs. 13-15). One study used this task in obese children, but this particular study lacks a suitable control group of lean children (16).

For the present study, we examined whether overweight/ obese participants work harder for high-calorie snacks compared to a normal-weight control group. If so, this would imply that the relative-reinforcing value of high-calorie snacks is higher for overweight/obese individuals than normal-weight individuals. To investigate this hypothesis an overweight/obese group and a normal-weight control group performed a concurrent schedules task with tasty high-calorie foods (snack food) and tasty low-calorie foods (fruit and vegetables) as choice options. By gradually increasing the amount of work required to earn the high-calorie snacks, the reinforcing value of tasty snacks relative to tasty fruits and vegetables was determined.

\section{METHODS AND PROCEDURES}

\section{Participants}

A total of 88 undergraduate students from Maastricht University were invited to take part in a so-called study on choice behavior and mental fatigue. When doing so, they in fact took part in two separate experiments: the present study and another unrelated study using a behavioral reaction time task to indirectly measure participants' evaluation of different food items, results of which will be reported elsewhere.
Students were selected based on self-reported BMI $\left(\mathrm{kg} / \mathrm{m}^{2}\right)$. We tried to select as many candidates with a self-reported BMI $\geq 25$ as candidates with a self-reported BMI $<25$, preferably around 20 to make sure to obtain two distinct groups. Participants' actual BMI was measured at the end of participation and the assignment of participants to either the overweight/obese condition or the lean condition was determined on the basis of these actual BMIs. Participants with a BMI $\geq 25$ were classified as overweight or obese, participants with a BMI $<25$ and were classified as normal weight.

Participants had to work for food (high- and low-calorie foods) during this experiment. Based on a taste test as described below, participants would work for their highest liked snack food and their highest liked low-calorie food (i.e., fruit or vegetable). Because it is important to keep the liking for the high- and low-calorie foods equal, we used the inclusion criterion that the highest liked snack food should not differ more than one point on an 11-point liking Likert scale from the highest liked fruit or vegetable. In total, 59 from the 88 students met this inclusion criterion. However, three participants did not follow the instructions to refrain from food $2 \mathrm{~h}$ before the experiment and one participant was on a specific diet to gain weight. Data from these four participants were excluded from the analysis, leaving us with 55 participants, 23 (12 male) in the obese/ overweight group and 32 (14 male) in the normal-weight control group. Participant characteristics are reported in Table 1.

\section{Materials and measurements}

Foods. Participants were presented with bite-size portions of eight different food items: four items from the category "fruit and vegetables" (cucumber $( \pm 4 \mathrm{~g})$, tangerines $( \pm 5 \mathrm{~g})$, white grapes $( \pm 6 \mathrm{~g})$, and canned pineapple chunks $( \pm 6 \mathrm{~g}$ ) (Del Monte Foods, San Francisco, CA)) and four items from the category "snack food" (chocolate M\&M's $( \pm 3 \mathrm{~g})$ (Masterfoods, Veghel, the Netherlands), chocolate chip cookies $( \pm 3 \mathrm{~g})$ (Van Welzen, Smilde Bakery, Edam), paprika flavored chips $( \pm 2 \mathrm{~g})$ (Lay's; Smiths Food Group, Utrecht, the Netherlands), and cocktail snacks $( \pm 2 \mathrm{~g})$ (Duyvis Productions, Zaandam, the Netherlands)). These eight foods were presented in random order on a tray.

We were careful not to explicitly refer to the food as "snack foods" vs. "fruit and vegetables," as to prevent participants from thinking that we were mainly interested in healthful choice behavior.

Rating and ranking task. Participants were asked to rate how much they momentarily liked the food on a paper-and-pencil task (11-points scale: 0 "not at all palatable at the moment" to 10 "highly palatable at the moment"). This rating task was followed by a ranking task, where the participant was asked to rank the eight food items from most palatable to least palatable at this moment.

Hunger. Participants were asked to indicate their momentary hunger on a 100 -mm visual analogue scale (0 "not at all hungry" to 100 "very hungry"). Hunger can influence the reinforcing value of food (17) or food reward (18) and in this way we were able to check whether

Table 1 Means with s.e., range, and $t$-tests of group characteristics

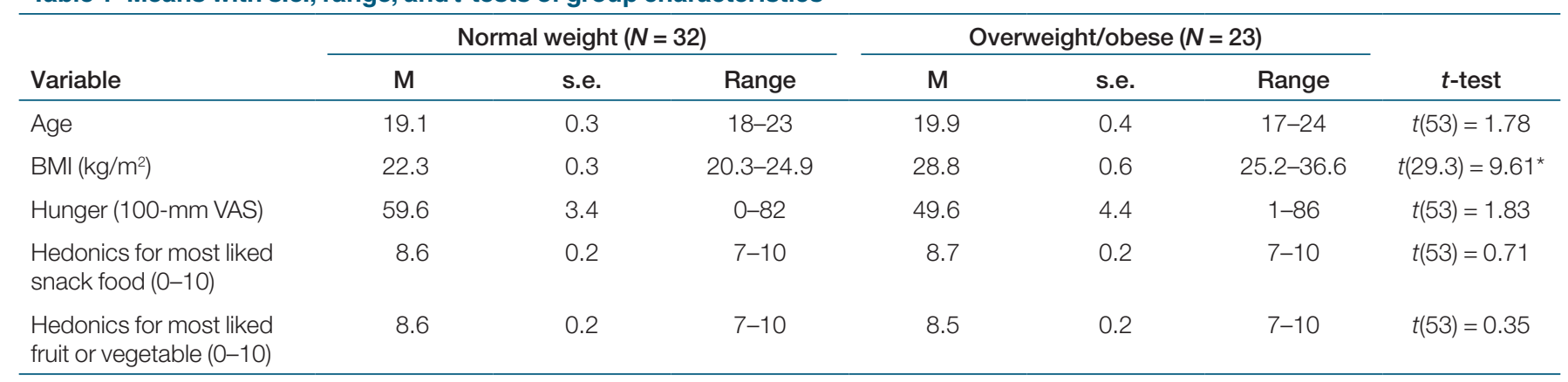

VAS, visual analogue scale.

${ }^{\star} P<0.001$ 
the groups did not differ on initial hunger and to control for possible variations in hunger.

Concurrent schedules task. Participants performed the concurrent schedules task with their favorite fruit or vegetable and their favorite snack, provided that the discrepancy in subjective liking between these two food items was $\leq 1$ point as described above. Participants were told that the computer would randomly select two of the eight food items that they had just sampled and they were told that they had to earn points that represented the two different foods in this task.

The task consisted of five schedules and each schedule comprised of making a series of choices. For each choice, a picture of the highcalorie snack and fruit/vegetable alternative was presented on screen and the participant was instructed to press the key corresponding to either one of the food options; that is, a left response key corresponding with the high-caloric snack or a right response key corresponding with the low-caloric alternative or vice versa with assignment of key (left or right) to caloric density (high or low) being randomly determined for each separate participant. Immediately after the key press, participants would receive feedback indicating whether they had earned a point for the food item, or not.

In the first schedule the reinforcement ratio for snacks and fruit or vegetables were both set at FR2 (fixed ratio of 2), meaning that with every two responses on the same key a point was earned for the corresponding food. This FR2 reinforcement schedule remained the same for the fruit and vegetable option throughout the task. However, the response requirement for the high-caloric snack option doubled with every schedule, meaning that in the fifth and final schedule a participant would have to push a key twice to obtain a fruit or vegetable point and 32 times (FR32) on the other response key to earn one point for snacks.

Participants were informed that as the game proceeded it would get harder to earn points for one of the two options. Participants were explained that every 10 points equals $10 \mathrm{~g}$ of the matching food and that they would have to eat the food that was earned after the game. In every schedule 20 points in total (snack points + fruit/vegetable points) had to be earned before proceeding to the next schedule, meaning that a total of 100 points and thus $100 \mathrm{~g}$ of food had to be eaten directly after the task. This instruction served to limit the probability of socially desirable responding by the participant during the task.

\section{Procedure}

When invited, participants were instructed to eat $2 \mathrm{~h}$ before the experiment and from that time on to refrain from food until participation. Participants were tested individually between noon and 6PM. At arrival, participants were presented with the eight food items and were instructed to taste the foods and fill in the rating and ranking task. This was followed by the hunger measurement and a filler-questionnaire about choice behavior in line with the cover story. This questionnaire allowed the experimenter time to enter the personal favorite fruit or vegetable and favorite snack as choice options in the concurrent schedules task. When finished with this filler questionnaire, participants were left alone to perform the concurrent schedules task. After performing the computer game, when having earned a total of 100 food points (snack + fruit/vegetable points), participants received a second behavioral reaction time task pertaining to another unrelated research question, results of which will be reported elsewhere as noted above. After the reaction time task, participants exchanged the points they had earned previously for the foods and ate it accordingly. Although we asked participants explicitly not to discuss the experiment afterwards, we chose to have the participants actually eat the food they earned to ensure that they would not tell other (potential) participants that the choices they made did not matter. When having finished eating the foods, participants' height and weight were measured to calculate BMI $\left(\mathrm{kg} / \mathrm{m}^{2}\right)$.

Participants received one course credit or a $€ 7.50$ monetary voucher as remuneration for their participation. This study was approved by the research ethics committee of the Faculty of Psychology and Neuroscience of Maastricht University.

\section{RESULTS}

To check whether liking for the snack and fruit or vegetable indeed was similar, we performed a 2 (liking: snack vs. fruit/ vegetable) $\times 2$ (group: normal weight vs. overweight/obese) ANOVA, which showed no significant interaction effect of liking $\times$ group, $F(1,53)=1.40, P=0.242, \eta_{p}{ }^{2}\left(\right.$ partial $\left.\eta^{2}\right)=0.026$, and no main effect of liking, $F(1,53)=1.40, P=0.242, \eta_{\mathrm{p}}{ }^{2}=$ 0.026 or group, $F(1,53)=0.04, P=0.835, \eta_{p}{ }^{2}=0.001$. This indicates that indeed the liking for the snack was similar to the liking for the fruit or vegetable.

To test our hypothesis that overweight/obese individuals work harder for snack food than normal-weight individuals we performed a schedule $\times$ group $\times$ hunger analysis of covariance, with number of responses for snack food as dependent variable. This analysis revealed significant main effects of schedule $F(1.84,95.67)=12.21, P<0.001, \eta_{\mathrm{p}}{ }^{2}=0.190$ and group $F(1,52)=6.84, P=0.012, \eta_{\mathrm{p}}{ }^{2}=0.116$, which were qualified by a marginally significant schedule $\times$ group interaction effect, $F(1.84,95.67)=2.64, P=0.081, \eta_{p}{ }^{2}=0.048$. This implies that the more work was required to obtain snack points, the harder the overweight/obese participants tended to work for snack points as compared to normal-weight control participants. Mean number of responses per schedule for each group is displayed in Figure 1. The analysis revealed neither a significant main effect of the covariate hunger nor a significant interaction effect of hunger by group, largest $F=2.14$.

Post hoc tests show that there were no differences between groups in responding for snacks during the first two schedules FR2 and FR4, $F(1,52) \leq 2.13, P \geq 0.150, \eta_{p}{ }^{2} \leq 0.039$. The two groups, however, did differ on the last three schedules, FR8, FR16, and FR32: $F(1,52) \geq 4.11, P \leq 0.048, \eta_{p}{ }^{2} \geq 0.073$. The covariate hunger was only significant for the FR2 schedule, $F(1,52)=4.39, P=0.041, \eta_{p}^{2}=0.078$.

Further, using mixed effects regression models, elasticity of demand for snacks was determined. Elasticity of demand is the change in consumption of a reinforcer relative to its price change (19). Log values of the number of reinforcers obtained
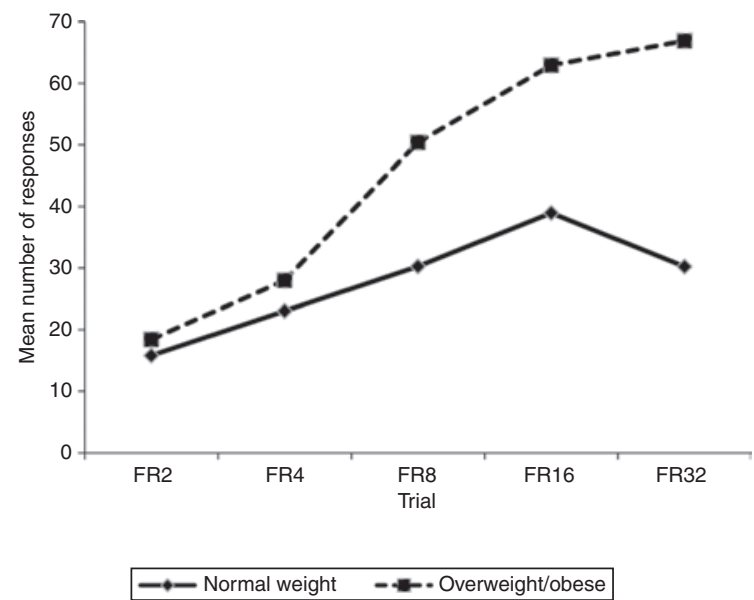

Figure 1 Mean number of responses for snack food per schedule for each group. FR refers to fixed ratio of reinforcement and the numbers refer to the number of responses required to earn a single-snack point. 
and of the reinforcement ratios for snacks were used in the regression models. The typical regression equation looks like:

Ln Reinforcers $=\alpha+\beta_{1}$ (Ln FR) $+\beta_{2}$ (group) $+\beta_{3}$ (hunger) + $\beta_{4}(($ Ln FR $) \times$ group $)+\beta_{5}(($ Ln FR $) \times$ hunger $)+\beta_{6}($ group $\times$ hunger $)+\beta_{7}(($ Ln FR $) \times$ group $\times$ hunger $)$. Here $\beta_{1}$ represents the demand elasticity. We tested two types of elasticity; own-price elasticity, when snack reinforcers are the dependent variable, and cross-price elasticity (19), when fruit/vegetables reinforcers are the dependent variable. Analyses were first performed with all interactions in the model, but if these interactions were not significant they were removed from the model. Only significant interactions are reported. Note that all independent predictors remained in the model.

For the regression model with snack reinforcers as dependent variable, the estimate for own-price elasticity was significant (estimate $=-0.607, P<0.001$ ), meaning that when more work was required for snacks, the demand for snacks decreased. Group was a significant predictor of demand for snacks (estimate $=0.135, P=0.021$ ), meaning that the overweight/ obese participants had a higher demand for snacks than the normal-weight control participants. For the regression model with fruit/vegetables reinforcers as dependent variable, the estimate for cross-price elasticity was significant (estimate $=0.189, P<$ 0.001 ), meaning that when more work was required for snacks, the demand for fruit/vegetables increased, suggesting that fruit/ vegetables are substitutes for snacks. Group was a significant predictor of demand for fruit/vegetables (estimate $=-0.049$, $P=0.011$ ), meaning that the overweight/obese participants had a lower demand for fruit/vegetables than the normal-weight control participants. However, the hypothesized Ln FR $\times$ group interaction did not materialize. Hunger was also a significant predictor of the demand for fruit/vegetables (estimate $=-0.003$, $P=0.002)$, which means that the more hungry participants were, the lower the demand for fruit/vegetables was, this effect was qualified by a significant interaction effect of Ln FR $\times$ hunger (estimate $=0.002, P=0.031$ ). This is in line with the findings from the post hoc tests that hunger was a significant covariate on the first schedule (FR2) and not on the other schedules.

\section{DISCUSSION}

In this study, we hypothesized that the relative-reinforcing value of high-calorie snacks is higher for overweight/obese individuals compared to normal-weight controls. The results from this study show that overweight/obese individuals indeed work harder to obtain snack food compared to the normal-weight controls, confirming our hypothesis. Moreover, this difference in the relative-reinforcing value of snack foods was apparent in the absence of a difference in explicit liking for the highcalorie food, which is in line with the notion that overweight/ obese show exaggerated high-calorie food wanting. This finding also stresses the notion that the value of a reinforcer cannot be equated with its palatability. Further, the analyses on the demand for snack food show that when snacks are harder to get participants substitute snacks with fruit/vegetables. In addition, the demand for snacks is higher for overweight/obese participants than for normal-weight controls.
Further, from this study it can be concluded that compared to normal-weight individuals, overweight/obese individuals are sensitive specifically to the reinforcing value of high-calorie snack foods and not food in general. It seems that even when normal-weight individuals like the snacks and also the fruit/ vegetables as much as the overweight/obese individuals, overweight/obese individuals are prepared to put more effort into obtaining snack food. These findings suggest that high-calorie food wanting, independent of liking, may contribute to the overconsumption of high-calorie foods in overweight/obesity.

Note that the present pattern of results does not allow us to conclude that, within participants, the reinforcing value of snacks is higher than the reinforcing value of low-calorie foods, because our design did not include a condition in which the response requirement for the fruit and vegetables option was increased relative to the snack option. This then means that it is possible that overweight/obese participants would also work harder for low-calorie foods with an increase in response requirement. However, this is improbable, because that would imply that overweight/obese individuals are more likely to invest energy into acquiring anything that becomes incrementally more difficult to obtain.

Interestingly, the finding that overweight/obese individuals work harder for high-calorie foods compared to normal-weight controls is in line with the findings from la Fleur et al. (20), who found a positive correlation between working for sucrose and weight gain in rats. la Fleur and colleagues found that when rats consumed a high-caloric diet for a few weeks, they started working harder for sucrose. According to these researchers, the more a rat is motivated to work for high-fat foods the more obese the rat will become, and the more obese the rat becomes the more it will want to work for food. A recent study (21) found that the relative-reinforcing value of food does predict weight changes in children over a period of 1 year. Whether this is also the case for adults and on a longer time frame is not known yet. The current study is a correlational study, and therefore we cannot conclude whether a high-reinforcing value for snack food causes overeating or vice versa, or that a third factor (e.g., dietary restraint) correlating with BMI accounts for the results.

It must be noted that the present study used a sample of university students with a restricted age range, which limits the generalizability of the findings. Moreover, in our sample of overweight/obese participants, only a third was obese, therefore there are limitations to comparing these results to other studies with samples of only obese participants.

In conclusion, the present study supports the notion that the relative-reinforcing value of snack foods is higher for overweight/obese individuals compared to normal-weight individuals, even when liking for the food is equal. These findings may be relevant to understand overeating in obesity. Simply providing more palatable low-calorie foods will probably not help in curbing the obesity epidemic. Decreasing the reinforcing value of snack food seems to be a more viable solution. Lowering the reinforcing value for snack foods could be accomplished by increasing the associated costs with these foods (22). Whether 
this is indeed beneficial in the treatment of obesity awaits empirical validation.

\section{DISCLOSURE}

The authors declared no conflict of interest.

(C) 2010 The Obesity Society

\section{REFERENCES}

1. Jéquier E. Pathways to obesity. Int J Obes Relat Metab Disord 2002;26 Suppl 2:S12-S17.

2. Drewnowski A. The behavioral phenotype in human obesity. In: Capaldi ED (ed). Why We Eat What We Eat: The Psychology of Eating. American Psychological Association: Washington, DC, 1996, pp 291-308.

3. Drewnowski A, Kurth C, Holden-Wiltse J, Saari J. Food preferences in human obesity: carbohydrates versus fats. Appetite 1992;18:207-221.

4. Rissanen A, Hakala P, Lissner L et al. Acquired preference especially for dietary fat and obesity: a study of weight-discordant monozygotic twin pairs. Int J Obes Relat Metab Disord 2002;26:973-977.

5. Berridge KC. Food reward: brain substrates of wanting and liking. Neurosci Biobehav Rev 1996;20:1-25.

6. Berridge KC. Brain reward systems for food incentives and hedonics in normal appetite and eating disorders. In: Kirkham TC, Cooper SJ (eds). Progress in Brain Research: Appetite and Body Weight. Academic Press: New York, 2007, pp 191-216

7. Mela DJ. Eating for pleasure or just wanting to eat? Reconsidering sensory hedonic responses as a driver of obesity. Appetite 2006;47: 10-17.

8. Roefs A, Jansen A. Implicit and explicit attitudes toward high-fat foods in obesity. J Abnorm Psychol 2002;111:517-521.

9. Hill C, Wardle J, Cooke L. Adiposity is not associated with children's reported liking for selected foods. Appetite 2009;52:603-608.
10. Epstein LH, Truesdale R, Wojcik A, Paluch RA, Raynor HA. Effects of deprivation on hedonics and reinforcing value of food. Physiol Behav 2003;78:221-227.

11. Havermans RC, Janssen T, Giesen JCAH, Roefs A, Jansen A. Food liking, food wanting, and sensory-specific satiety. Appetite 2009;52:222-225.

12. Saelens BE, Epstein LH. Reinforcing value of food in obese and non-obese women. Appetite 1996;27:41-50.

13. Giesen JCAH, Havermans RC, Nederkoorn C, Strafaci S, Jansen A. Working harder to obtain more snack foods when wanting to eat less. Behav Res Ther 2009;47:13-17.

14. Goldfield GS, Epstein LH. Can fruits and vegetables and activities substitute for snack foods? Health Psychol 2002;21:299-303.

15. Raynor HA, Epstein $\mathrm{LH}$. The relative-reinforcing value of food under differing levels of food deprivation and restriction. Appetite 2003;40:15-24.

16. Smith JA, Epstein LH. Behavioral economic analysis of food choice in obese children. Appetite 1991;17:91-95.

17. Lappalainen R, Epstein LH. A behavioral economics analysis of food choice in humans. Appetite 1990;14:81-93.

18. Siep N, Roefs A, Roebroeck A et al. Hunger is the best spice: an fMRI study of the effects of attention, hunger and calorie content on food reward processing in the amygdala and orbitofrontal cortex. Behav Brain Res 2009;198:149-158.

19. Johnson MW, Bickel WK. Replacing relative reinforcing efficacy with behavioral economic demand curves. J Exp Anal Behav 2006;85:73-93.

20. la Fleur SE, Vanderschuren LJ, Luijendijk MC et al. A reciprocal interaction between food-motivated behavior and diet-induced obesity. Int J Obes (Lond) 2007;31:1286-1294.

21. Hill C, Saxton J, Webber L, Blundell J, Wardle J. The relative reinforcing value of food predicts weight gain in a longitudinal study of 7-10-y-old children. Am J Clin Nutr 2009;90:276-281.

22. Giesen JCAH, Havermans RC, Jansen A. Substituting snacks with strawberries and sudoku's: Does restraint matter? Health Psychol, in press. 